Research Article Published July 13, 2016

\title{
Rosuvastatin Decreases Intestinal Fatty Acid Binding Protein (I-FABP), but Does Not Alter Zonulin or Lipopolysaccharide Binding Protein (LBP) Levels, in HIV-Infected Subjects on Antiretroviral Therapy
}

\section{STANDFIRST}

Rosuvastatin treatment does not appear to improve GI-integrity in persons infected with HIV.

\section{AUTHORS}

Nicholas T. Funderburg ${ }^{1}$, Morgan Boucher ${ }^{1}$, Abdus Sattar ${ }^{2}$, Manjusha Kulkarni ${ }^{1}$, Danielle Labbato $^{2,3,4}$, Bruce I. Kinley ${ }^{2,3,4}$, Grace A. McComsey $y^{2,3,4}$

\section{AFFILIATED INSTITUTIONS}

${ }^{1}$ School of Health and Rehabilitation Sciences, Division of Medical Laboratory Science, Ohio State University, Columbus, Ohio

${ }^{2}$ Case Western Reserve University, Cleveland, Ohio

${ }^{3}$ University Hospitals Case Medical Center, Cleveland, Ohio

${ }^{4}$ Rainbow Babies and Children's Hospital, Cleveland, Ohio

\section{CORRESPONDING AUTHOR}

Grace A. McComsey, MD, FIDSA

Professor of Pediatrics and Medicine

Rainbow Babies and Children's Hospital

11100 Euclid Avenue

Cleveland, $\mathrm{OH}, 44106$.

Phone: 216-844-3607

Fax: 216-844-8362

E-mail: grace.mccomsey@,case.edu
DOI

10.20411/pai.v1i1.124 


\section{ABSTRACT}

Introduction: Altered gastrointestinal (GI) barrier integrity and subsequent microbial translocation may contribute to immune activation in HIV infection. We have reported that rosuvastatin improved several markers of immune activation in HIV+ participants, but the effect of statin treatment on markers of GI barrier dysfunction is unknown.

Methods: SATURN-HIV is a randomized, double-blind, placebo-controlled trial assessing the effect of rosuvastatin (10 mg/daily) on markers of cardiovascular disease, inflammation, and immune activation in ART-treated patients. Gut-barrier integrity was assessed by the surrogate markers intestinal fatty acid binding protein (I-FABP), a marker of enterocyte death, and zonulin-1, a marker of gut epithelial cell function. Levels of lipopolysaccharide binding protein (LBP) were measured as a marker of microbial translocation.

Results: Rosuvastatin significantly reduced levels of I-FABP during the treatment period compared to the placebo. There was no effect of rosuvastatin treatment on levels of zonulin or LBP. Baseline levels of LBP were directly related to several markers of immune activation in samples from all participants, including soluble CD163, IP-10, VCAM-1, TNFR-II, and the proportion of CD4+ and CD8+ T cells expressing CD38 and HLA-DR. Many of these relationships, however, were not seen in the statin arm alone at baseline or over time, as inflammatory markers often decreased and LBP levels were unchanged.

Conclusions: Forty-eight weeks of rosuvastatin treatment reduced levels of I-FABP, but did not affect levels of zonulin or LBP. The reduction in levels of inflammatory markers that we have reported with rosuvastatin treatment is likely mediated through other mechanisms not related to gut integrity or microbial translocation.

\section{KEYWORDS}

HIV-1, rosuvastatin, zonulin-1, intestinal fatty acid binding protein, lipopolysaccharide binding protein, inflammation

SATURN-HIV is registered on clinicaltrials.gov; Identifier: NCT01218802

\section{INTRODUCTION}

Immune activation and inflammation are hallmarks of chronic HIV infection, even when HIV+ individuals are receiving suppressive antiretroviral therapy (ART) $[1,2]$. Several markers of immune activation, including interleukin-6 (IL-6), soluble CD14 (sCD14), and markers of T-cell activation, are associated with mortality in this population [ $\underline{3}, \underline{4}]$. Strategies to reduce immune activation in ART-treated HIV infection are being explored. Statins, or 3-hydroxy-3-methylglutaryl coenzyme A (HMG-CoA) reductase inhibitors, have anti-inflammatory effects [ $[\underline{6}, \underline{6}]$, and within the Stopping Atherosclerosis and Treating Unhealthy bone with RosuvastatiN in HIV (SATURN-HIV) trial, we have reported significant reductions in monocyte (sCD14 and tissue factor expression) and T-cell activation (CD38 and HLA-DR on CD4+ and CD8+ cells) and vascular inflammation (lipoprotein-associated phospholipase A 2 [Lp-PLA $\left.{ }_{2}\right]$ ) following initiation of statin therapy [7-9]. The mechanism(s) related to statin-induced reduction of immune activation in HIV infection remain incompletely understood. 
There are likely multiple contributors to immune activation in ART-treated HIV infection, including: low level HIV-1 replication [10]; copathogens [11]; pro-inflammatory lipids (e.g., oxidized LDL) $[12,13]$; and microbial translocation [14]. Decreased GI integrity leads to increased circulating levels of lipopolysaccharide (LPS) in persons infected with HIV [15], and while ART often reduces plasma levels of LPS, these levels do not always normalize [16]. Plasma levels of LPS are directly related to T-cell and monocyte activation markers-including markers that predict mortality in HIV-infected individuals [17] — and LPS levels are related to coagulation markers in SIV-infected nonhuman primates [18]. Further, markers of gut epithelial barrier integrity (intestinal fatty acid binding protein [I-FABP] and zonulin-1) are also related to mortality in HIV-infected individuals [19]. We have reported previously that 48 weeks of statin therapy reduces cellular and plasma markers of monocyte, endothelial cell, and T-cell activation [7-9]. Here, we measured plasma levels of I-FABP, a marker of enterocyte death [20], zonulin-1, a marker of enterocyte function [21], and lipopolysaccharide binding protein (LBP), in order to determine whether the effect of statin therapy on reducing immune activation is mediated by improvement of GI integrity and reduction of microbial translocation.

\section{MATERIALS AND METHODS}

\section{Study Design}

Details of the trial design have been published [7-9]; in brief, SATURN-HIV is a randomized, double-blind, placebo-controlled study designed to measure the effect of rosuvastatin (10mg/ day) on markers of cardiovascular risk, skeletal health, and immune activation in HIV disease, and is registered on clinicaltrials.gov, Identifier: NCT01218802. SATURN-HIV was approved by the Institutional Review Board of University Hospitals Case Medical Center (Cleveland, OH) and all subjects signed a written consent prior to enrollment. The study was a 96 week trial that began with enrolling patients on 3/24/2011 and ended on 6/5/2014. Study drugs (active and placebo) were provided by AstraZeneca. All subjects were on stable ART for at least 3 months and cumulative ART duration of at least 6 months, with HIV-1 RNA $<1,000$ copies/mL, with fasting LDL-cholesterol (LDL-C) $\leq 130 \mathrm{mg} / \mathrm{dL}$ and fasting triglycerides $\leq 500 \mathrm{mg} / \mathrm{dL}$. Additional entry criteria included evidence of either heightened T-cell activation, identified as the proportion of CD8+ T cells that expressed CD38+HLA-DR $+\geq 19 \%$, or levels of high sensitivity C-reactive protein (hs-CRP) $\geq 2 \mathrm{mg} / \mathrm{L}$. Exclusion criteria included diabetes and known CVD.

\section{Blood/Sample Preparation}

Whole blood samples were collected into EDTA-containing tubes. Plasma was isolated by centrifugation for 10 minutes at $400 \mathrm{xg}$ and was frozen at $-80^{\circ} \mathrm{C}$ until thawed once and analyzed in batch. Plasma samples were collected at baseline, and at 24 and 48 weeks. Levels of zonulin-1 (ALPCO, Salem, NH), I-FABP (R\&D Systems human FABP2 Duoset ELISA system: Minneapolis MN), and LBP (Hycult Biotech, Plymouth Meeting, PA) were measured by enzyme-linked immunosorbent assays (ELISA). Other plasma markers and cellular markers of immune activation were measured and have been described previously []. Levels of soluble CD14 and CD163 were measured using Quantikine enzyme-linked immunosorbant assay (ELISA) kits (R\&D Systems, Minneapolis MN); levels of the proinflammatory cytokine IL-6 and soluble receptors of tumor necrosis factor a (sTNFR-I and sTNFR-II), interferon $\gamma$-inducible protein 10 (IP-10), the cellular adhesion molecules soluble vascular cell adhesion molecule 1 (sVCAM-1) and soluble intercellular adhesion molecule 1 (sICAM-1) were also measured by ELISAs (R\&D Systems, Minneapolis, MN). 


\section{T-Cell Phenotyping}

The proportion of activated T cells required to determine eligibility was measured by analyses of freshly collected whole blood samples, processed as above. T cells were identified by size and granularity and by positive expression of CD3 and CD4 or CD8. T-cell activation was measured using anti-CD38 (PE), anti-HLA-DR (FITC), anti-CD3 (Peridinin Chlorophyll Protein Complex, PerCP), anti-CD8 (allophycocyanin-cy7, APC-cy7), and anti-CD4 (allophycocyanin, APC, all from BD Biosciences).

Assessment of T-cell activation for the entry, 24-, and 48-week timepoints was performed by comparing the expression of surface markers on cryopreserved PBMC samples from each patient. Samples were thawed and analyzed in batch. In addition to the T-cell markers described above, analysis of frozen PBMC samples also included a stain for cell viability (Live/Dead Violet, Pacific Blue) and an additional activation marker PD-1 (PE-Cy7, BD Pharmingen). Samples were analyzed using a Miltenyi MACS Quant flow cytometer (MiltenyiBiotec, BergischGladbach, Germany). MACS Quantify software (version 2.21031.1, MiltenyiBiotec) was used to analyze the data.

\section{STATISTICAL METHODS}

Demographics, clinical characteristics, fasting metabolic parameters, and inflammatory and coagulation markers are described by study group. Continuous measures are described by medians and interquartile ranges, and nominal variables are described with frequencies and percentages.

Nominal variables were compared using $\chi^{2}$ analysis or Fisher's exact test. Continuous measures were tested for normality. For between-group comparisons (at baseline and changes from baseline to 48 weeks), normally-distributed variables were compared using t-tests, and non-normally-distributed variables were compared using Wilcoxon rank sum tests. For within-group changes from baseline to 48 weeks, normally-distributed variables were compared with a paired t-test, and non-normally-distributed variables were compared with Wilcoxon signed rank test. The non-parametric Spearman correlation was used to estimate correlations among changes in markers of inflammation and immune activation at week 48. Longitudinal changes in gut integrity biomarkers (IFAB, zonulin, and LBP) for rosuvastatin treatment were studied using the generalized estimating equation approach [2]. For visual comparison, the changes in gut biomarkers were also studied using graphs (box plot) over the 48-week period between the treatment groups.

All analyses were done using statistical software SAS 9.3 (SAS Institute Inc., Cary, NC, USA) and statistical software Stata 13.0 (College Station, TX).

\section{RESULTS}

Baseline demographic and immunologic characteristics of study subjects have been published [7-9]; in brief, 147 participants were enrolled in the SATURN-HIV study ( $n=72$ in the rosuvastatin arm; $n=75$ in the placebo arm). Overall, the median age of the participants was 47 years, $78 \%$ were male, 70\% were African American, 29\% were Caucasian, and 1\% were Hispanic. There were no differences in markers of GI-integrity or microbial translocation at baseline between the study arms. Among all participants, baseline plasma levels of LBP were directly related to plasma levels of: interferon gamma induced protein 10 (IP-10, $\mathrm{r}=0.25, P=0.007)$; tumor necrosis factor alpha receptor-II (TNFR-II, $\mathrm{r}=0.2, P=0.03$ ); markers of monocyte activation (sCD163, $\mathrm{r}=0.22, P=0.015$ ); 
endothelial cell activation (ICAM-1, $\mathrm{r}=0.19, P=0.04$; VCAM-1, $\mathrm{r}=0.21, P=0.02$ ); and the proportion of CD4+ $(\mathrm{r}=0.21, P=0.03)$ and $\mathrm{CD} 8+(\mathrm{r}=0.25, P=0.007) \mathrm{T}$ cells that expressed HLA-DR and CD38 (Figure 1). Among participants in the statin arm, only the relationships between LBP and sCD163 ( $\mathrm{r}=0.3, P=0.019)$ and LBP and IP-10 ( $\mathrm{r}=0.27, P=0.034)$ were significant. Baseline levels of I-FABP were inversely related to IP-10 levels ( $r=-0.18, P=0.05$, not shown). Baseline levels of zonulin did not correlate with any of the markers we measured.

A)

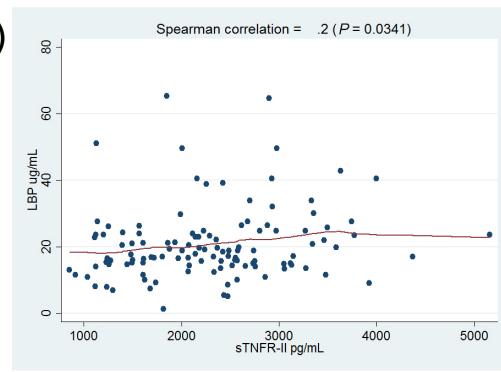

C)

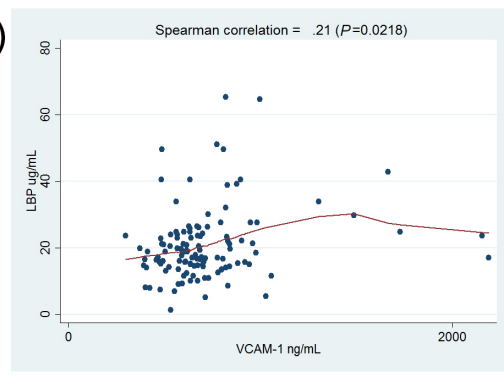

E)

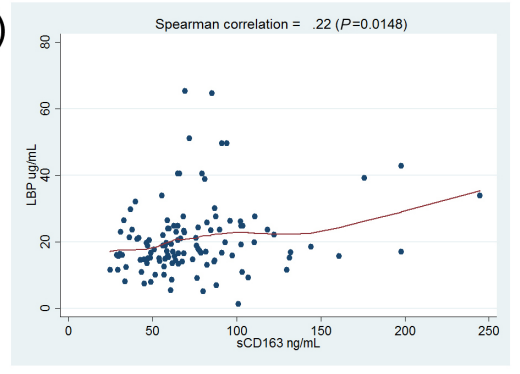

B)

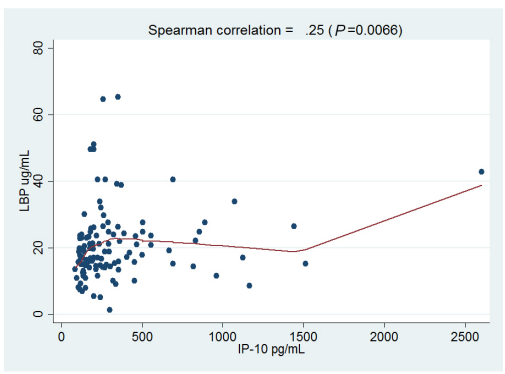

D)

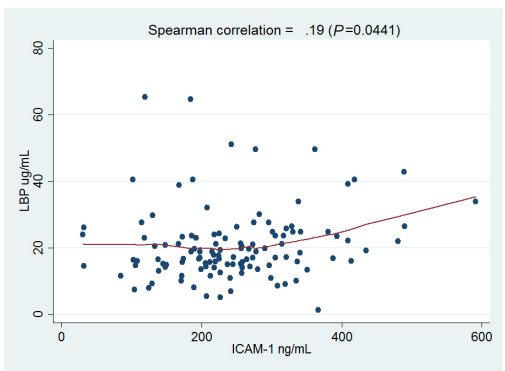

F)

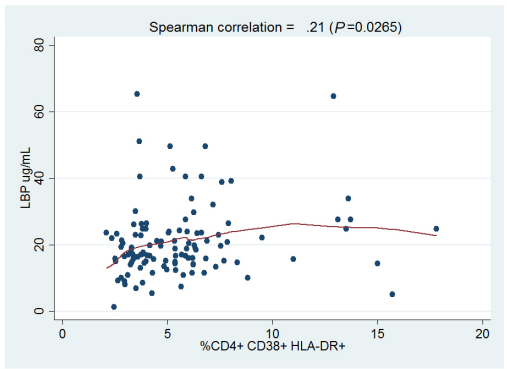

G)

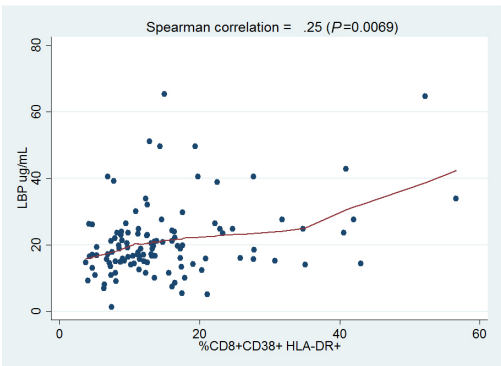

Figure 1. Plasma levels of lipopolysaccharide binding protein (LBP) are related to markers of immune activation in HIV-infected patients. Plasma samples were thawed and levels of (A) TNFr-II, (B) IP-10, (C) VCAM-1, (D) ICAM-1, and (E) sCD163 were measured by ELISA. Measurement of T-cell activation was performed by flow cytometry to assess surface activation markers (CD38, HLA-DR) on cryopreserved (F) CD4+ and (G) CD8+ T cells. Correlations between markers at baseline were determined using Spearman rank correlation, and lines were fitted to the data points using locally weighted regression (LOWESS). 
Rosuvastatin treatment was associated with reduced levels of I-FABP, when compared to placebo, during the 48 -week treatment period ( $\beta=-1078.80 \mathrm{pg} / \mathrm{mL}, P=0.04$, Figure 2$)$. As I-FABP levels decreased overtime in the statin arm, we eventually measured an inverse relationship between sCD163 and I-FABP $(r=-0.21, P=0.02)$ at week 48 , but this relationship was driven by outliers within the data. Rosuvastatin treatment did not affect levels of LBP or zonulin, yet, a relationship between sCD163 and LBP was maintained at week 24, but became insignificant at week 48, likely due to the flat levels of LBP and a significant decrease in sCD163 at week 48 within the statin arm.

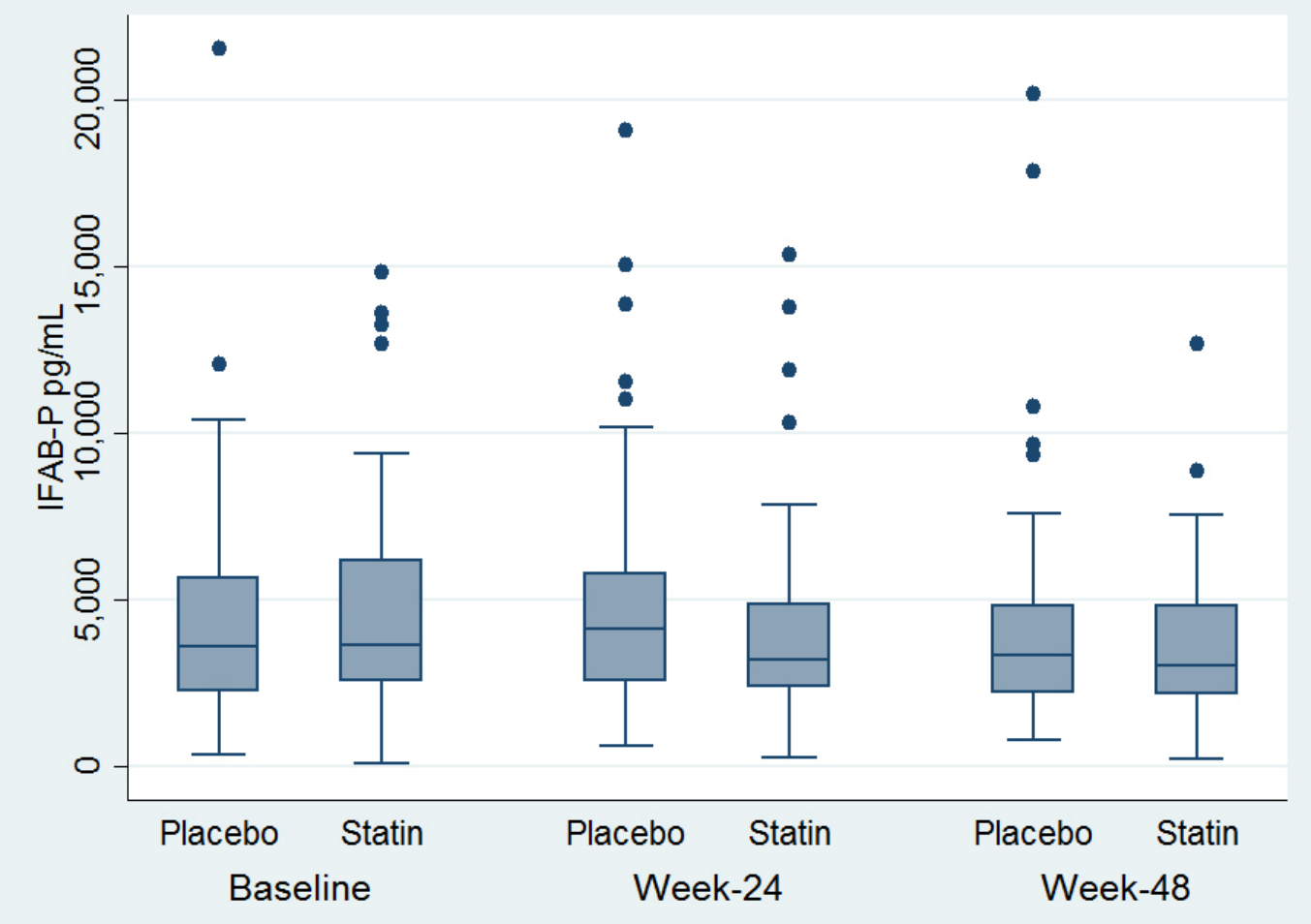

Figure 2. Rosuvastatin treatment reduces levels of I-FABP, but not levels of zonulin or LBP. Plasma samples were thawed and levels of intestinal fatty acid binding protein (I-FABP), zonulin, and lipopolysaccharide binding protein (LBP) were measured by ELISA. Rosuvastatin reduced levels of I-FABP over the study period compared to placebo. Levels of the other gut integrity markers did not change over time with statin treatment (not shown).

\section{DISCUSSION}

The SATURN-HIV study is a double blind, randomized, placebo-controlled clinical trial of rosuvastatin as an immunomodulatory therapy in HIV-infected subjects on ART. We have reported that rosuvastatin decreases plasma and cellular markers of monocyte $[\underline{8}, \underline{9}]$ and T-cell activation []ㅡ, lowers vascular inflammation [ $[\underline{8}, \underline{8}]$, preserves renal function, and lowers cystatin C levels [23] in ART-treated HIV-infected persons. The direct mechanisms by which statin therapy improves chronic immune activation in these study participants are not fully understood.

Here we tested the hypothesis that rosuvastatin may modulate immune activation by improving the integrity of the GI tract and subsequently reducing microbial translocation. Bacterial products 
derived from the gut lumen, and specifically plasma levels of LPS, are directly related to T-cell activation (CD38 and HLA-DR expression) [1두 17], to levels of soluble CD14 [17], and to proportions of CD16+ monocytes [17], and are inversely related to CD4+ T cell reconstitution following initiation of ART [24]. Alternatively, if levels of inflammation and immune activation can be reduced with rosuvastatin treatment, the GI tract may recover normal barrier function. Therefore, by looking at the changes in inflammatory markers and gut barrier integrity markers serially over time, we may be able to infer causality.

Several markers of impaired GI-function have been measured in HIV-infected individuals [19, 25]. Plasma levels of I-FABP are increased in HIV-infected donors compared to uninfected donors [20] and increased plasma levels of I-FABP may represent increased enterocyte death, which may contribute to impaired barrier function. Zonulin-1 is produced by viable gut epithelial cells and plays a part in regulating paracellular intestinal permeability [21] , and zonulin-1 has been found to be upregulated in different immune diseases that are characterized by chronic inflammation of the gut, including celiac disease [26]. Zonulin-1 and I-FABP levels are predictive of mortality in persons infected with HIV [19], so favorable modulation of their expression may improve clinical outcomes. We did not find statistically significant changes in zonulin-1 between the statin arm and the placebo arm. Levels of I-FABP decreased during statin treatment, which may represent decreased enterocyte death; perhaps 48 weeks of statin therapy is not long enough, or the local anti-inflammatory effect of rosuvastatin treatment was not potent enough to repair the GI tract sufficiently to measure changes in zonulin levels.

Levels of LBP, produced by hepatocytes in the liver, may reflect an attempt by the host to bind translocated LPS and clear it from the circulation [27]. Levels of LBP are increased in HIV-infected persons compared to uninfected controls [15] and LBP levels decrease following initiation of ART [28]. In our study, baseline levels of LBP were directly related to several markers of immune activation and inflammation (sCD163, CD38, and HLA-DR on T cells, among others) in all participants. Over 48 weeks of therapy, many inflammatory markers decreased with statin treatment [7-9], yet levels of LBP did not change significantly. Levels of sCD163 and LBP were directly related at week 24 , but became insignificant at week 48 , likely due to the flat levels of LBP and a significant decrease in sCD163 at week 48 within the statin arm. These baseline relationships did not persist over time, partially due to decreasing sample size (total population versus statin arm), but these results may also suggest that changes in microbial translocation and GI-function are not responsible for improvement in immune activation within these participants. This null result is made less surprising based on our recent findings that statin treatment reduces oxidized LDL (oxLDL) levels in these subjects [29], and that early changes in oxLDL levels were related to changes in soluble CD14 and intima-medial thickness of the carotid artery. This suggests that statin-mediated decreases in pro-inflammatory lipid profiles may be on the causal pathway for reduction in inflammation, monocyte activation, and cardiovascular disease in ART-treated HIV infection.

While our results suggest that rosuvastatin treatment may not improve GI-tract permeability and result in decreased levels of microbial translocation, this current study has a few important limitations. First, we did not directly measure any microbial products (LPS, $16 S$ rRNA, etc.) or their changes over time. These assays are technically complex and we chose not to perform them once we did not see significant changes in gut barrier markers. Second, binding and clearance of LPS from the circulation likely involves several mediators, including LBP, LPS binding antibod- 
ies (endoCab and secretory IgA), and lipid molecules [30]; measuring LBP alone likely does not provide a complete picture of the mechanisms of LPS clearance. We also did not directly measure endothelial cell/tissue structure, expression of gut barrier proteins, or the transcriptional profile of endothelial cells, which has been shown to be important in measuring GI permeability in HIV infection [31]. Further tests that directly measure barrier protein expression and/or GI permeability by lactulose/mannitol absorption [32] would be required to definitively assess GI barrier function; these assays are not possible in the current study.

Overall, our findings suggest that decreases in inflammation and immune activation in ART-treated HIV-infected persons following rosuvastatin treatment are not likely attributable to decreases in microbial translocation and improvements in GI-barrier function.

\section{AUTHOR CONTRIBUTIONS}

GM designed the study and obtained funding. MB, MK, and NTF performed the experiments. $\mathrm{BK}, \mathrm{DL}$, and GM obtained patient samples. AS provided statistical support. All authors contributed to data analysis and writing of the manuscript.

\section{POTENTIAL CONFLICTS OF INTEREST}

GAM has served as a scientific advisor for Bristol-Myers Squibb, GlaxoSmithKline/ViiV, Pfizer, ICON, and Gilead Sciences and has received research grants from Bristol-Myers Squibb, GlaxoSmithKline, and Gilead Sciences. NTF has served as a consultant for Gilead. All other authors declare no conflicts of interest.

\section{FINANCIAL SUPPORT}

The work was supported by the National Institutes of Health R01 NR012642 to GAM. Technical support was provided by the Center for AIDS Research, Case Western Reserve University (P30 AI36219 and AI68636). Research reported in this publication was supported by the National Heart, Lung, and Blood Institute of the National Institutes of Health under Award Number R00HL108743 to NTF. The content is solely the responsibility of the authors and does not necessarily represent the official views of the National Institutes of Health. Study drugs and matching placebo were donated by AstraZeneca.

\section{REFERENCES}

1. Lederman MM, Funderburg NT, Sekaly RP, Klatt NR, Hunt PW. Residual immune dysregulation syndrome in treated HIV infection. Adv Immunol. 2013;119:51-83. PubMed PMID: 23886064. doi: 10.1016/B978-0-12-407707-2.00002-3

2. Funderburg NT. Markers of coagulation and inflammation often remain elevated in ART-treated HIV-infected patients. Curr Opin HIV AIDS. 2013. PubMed PMID: 24275673. doi: 10.1097/COH.0000000000000019

3. Kuller LH, Tracy R, Belloso W, De Wit S, Drummond F, Lane HC, Ledergerber B, Lundgren J, Neuhaus J, Nixon D, Paton NI, Neaton JD. Inflammatory and coagulation biomarkers and mortality in patients with HIV infection. PLoS Med. 2008;5(10):e203. PubMed PMID: 18942885. 
4. Emery S, Neuhaus JA, Phillips AN, Babiker A, Cohen CJ, Gatell JM, Girard PM, Grund B, Law M, Losso MH, Palfreeman A, Wood R. Major clinical outcomes in antiretroviral therapy (ART)-naive participants and in those not receiving ART at baseline in the SMART study. J Infect Dis. 2008;197(8):1133-44. PubMed PMID: 18476292.

5. 5. Jain MK, Ridker PM. Anti-inflammatory effects of statins: clinical evidence and basic mechanisms. Nat Rev Drug Discov. 2005;4(12):977-87. PubMed PMID: 16341063. doi: $10.1038 / \operatorname{nrd} 1901$

6. Ridker PM, Danielson E, Fonseca FA, Genest J, Gotto AM, Jr, Kastelein JJ, Koenig W, Libby P, Lorenzatti AJ, MacFadyen JG, Nordestgaard BG, Shepherd J, Willerson JT, Glynn RJ. Rosuvastatin to prevent vascular events in men and women with elevated C-reactive protein. N Engl J Med. 2008;359(21):2195-207. PubMed PMID: 18997196. doi: 10.1056/NEJMoa0807646

7. Eckard AR, Jiang Y, Debanne SM, Funderburg NT, McComsey GA. Effect of 24 weeks of statin therapy on systemic and vascular inflammation in HIV-infected subjects receiving antiretroviral therapy. J Infect Dis. 2014;209(8):1156-64. PubMed PMID: 24415784. Pubmed Central PMCID: 3969551. doi: 10.1093/infdis/jiu012

8. Funderburg NT, Jiang Y, Debanne SM, Labbato D, Juchnowski S, Ferrari B, Clagett B, Robinson J, Lederman MM, McComsey GA. Rosuvastatin Reduces Vascular Inflammation and T-cell and Monocyte Activation in HIV-Infected Subjects on Antiretroviral Therapy. J Acquir Immune Defic Syndr. 2015;68(4):396-404. PubMed PMID: 25514794. Pubmed Central PMCID: 4334694. doi: 10.1097/QAI.0000000000000478

9. Funderburg NT, Jiang Y, Debanne SM, Storer N, Labbato D, Clagett B, Robinson J, Lederman MM, McComsey GA. Rosuvastatin Treatment Reduces Markers of Monocyte Activation in HIV-Infected Subjects on Antiretroviral Therapy. Clin Infect Dis. 2014;58(4):588-95. PubMed PMID: 24253250. Pubmed Central PMCID: 3905756. doi: $10.1093 / \mathrm{cid} / \mathrm{cit} 748$

10. Hatano H, Delwart EL, Norris PJ, Lee TH, Neilands TB, Kelley CF, Hunt PW, Hoh R, Linnen JM, Martin JN, Busch MP, Deeks SG. Evidence of persistent low-level viremia in long-term HAART-suppressed, HIV-infected individuals. AIDS. 2010;24(16):25359. PubMed PMID: 20651585. Pubmed Central PMCID: 2954261. doi: 10.1097/ QAD.0b013e32833dba03

11. Hunt PW, Martin JN, Sinclair E, Epling L, Teague J, Jacobson MA, Tracy RP, Corey L, Deeks SG. Valganciclovir reduces T cell activation in HIV-infected individuals with incomplete CD4+ T cell recovery on antiretroviral therapy. J Infect Dis. 2011;203(10):1474-83. PubMed PMID: 21502083. Pubmed Central PMCID: 3080892. doi: 10.1093/infdis/jir060

12. Piconi S, Parisotto S, Rizzardini G, Passerini S, Meraviglia P, Schiavini M, Niero F, Biasin M, Bonfanti P, Ricci ED, Trabattoni D, Clerici M. Atherosclerosis is associated with multiple pathogenic mechanisms in HIV-infected antiretroviral-naive or treated individuals. AIDS. 2013;27(3):381-9. PubMed PMID: 23079800. doi: 10.1097/ QAD.0b013e32835abcc9

13. Zidar DA, Juchnowski S, Ferrari B, Clagett B, Pilch-Cooper HA, Rose S, Rodri- 
guez B, McComsey GA, Sieg SF, Mehta NN, Lederman MM, Funderburg NT. Oxidized LDL levels are increased in HIV infection and may drive monocyte activation. J Acquir Immune Defic Syndr. 2015. PubMed PMID: 25647528. doi: 10.1097/ QAI.0000000000000566

14. Klatt NR, Funderburg NT, Brenchley JM. Microbial translocation, immune activation, and HIV disease. Trends Microbiol. 2013;21(1):6-13. PubMed PMID: 23062765. Pubmed Central PMCID: 3534808. doi: 10.1016/j.tim.2012.09.001

15. Brenchley JM, Price DA, Schacker TW, Asher TE, Silvestri G, Rao S, Kazzaz Z, Bornstein E, Lambotte O, Altmann D, Blazar BR, Rodriguez B, Teixeira-Johnson L, Landay A, Martin JN, Hecht FM, Picker LJ, Lederman MM, Deeks SG, Douek DC. Microbial translocation is a cause of systemic immune activation in chronic HIV infection. Nat Med. 2006. PubMed PMID: 17115046.

16. Funderburg NT, Andrade A, Chan ES, Rosenkranz SL, Lu D, Clagett B, Pilch-Cooper HA, Rodriguez B, Feinberg J, Daar E, Mellors J, Kuritzkes D, Jacobson JM, Lederman MM. Dynamics of immune reconstitution and activation markers in HIV+ treatment-naive patients treated with raltegravir, tenofovir disoproxil fumarate and emtricitabine. PLoS One. 2013;8(12):e83514. PubMed PMID: 24367599. Pubmed Central PMCID: 3867440. doi: 10.1371/journal.pone.0083514

17. Funderburg NT, Zidar DA, Shive C, Lioi A, Mudd J, Musselwhite LW, Simon DI, Costa MA, Rodriguez B, Sieg SF, Lederman MM. Shared monocyte subset phenotypes in HIV-1 infection and in uninfected subjects with acute coronary syndromes. Blood. 2012. PubMed PMID: 23065151. doi: 10.1182/blood-2012-05-433946

18. Pandrea I, Cornell E, Wilson C, Ribeiro RM, Ma D, Kristoff J, Xu C, Haret-Richter GS, Trichel A, Apetrei C, Landay A, Tracy R. Coagulation biomarkers predict disease progression in SIV-infected nonhuman primates. Blood. 2012;120(7):135766. PubMed PMID: 22653975. Pubmed Central PMCID: 3423778. doi: 10.1182/ blood-2012-03-414706

19. Hunt PW, Sinclair E, Rodriguez B, Shive C, Clagett B, Funderburg N, Robinson J, Huang Y, Epling L, Martin JN, Deeks SG, Meinert CL, Van Natta ML, Jabs DA, Lederman MM. Gut epithelial barrier dysfunction and innate immune activation predict mortality in treated HIV infection. J Infect Dis. 2014;210(8):1228-38. PubMed PMID: 24755434. Pubmed Central PMCID: 4192038. doi: 10.1093/infdis/jiu238

20. Sandler NG, Wand H, Roque A, Law M, Nason MC, Nixon DE, Pedersen C, Ruxrungtham K, Lewin SR, Emery S, Neaton JD, Brenchley JM, Deeks SG, Sereti I, Douek DC. Plasma levels of soluble CD14 independently predict mortality in HIV infection. J Infect Dis. 2011;203(6):780-90. PubMed PMID: 21252259. Pubmed Central PMCID: 3071127. doi: 10.1093/infdis/jiq118

21. Fasano A. Intestinal permeability and its regulation by zonulin: diagnostic and therapeutic implications. Clin Gastroenterol Hepatol. 2012;10(10):1096-100. PubMed PMID: 22902773. Pubmed Central PMCID: PMC3458511. doi: 10.1016/j. cgh.2012.08.012

22. Zeger SL, Liang KY. Longitudinal data analysis for discrete and continuous outcomes. 
Biometrics. 1986;42(1):121-30. PubMed PMID: 3719049.

23. Longenecker CT, Hileman CO, Funderburg NT, McComsey GA. Rosuvastatin preserves renal function and lowers cystatin $\mathrm{C}$ in $\mathrm{HIV}$-infected subjects on antiretroviral therapy: the SATURN-HIV trial. Clin Infect Dis. 2014;59(8):1148-56. PubMed PMID: 25015912. Pubmed Central PMCID: 4271099. doi: 10.1093/cid/ciu523

24. Hunt PW, Martin JN, Sinclair E, Bredt B, Hagos E, Lampiris H, Deeks SG. T cell activation is associated with lower CD4+ T cell gains in human immunodeficiency virus-infected patients with sustained viral suppression during antiretroviral therapy. J Infect Dis. 2003;187(10):1534-43. PubMed PMID: 12721933. doi: 10.1086/374786

25. Steele AK, Lee EJ, Vestal B, Hecht D, Dong Z, Rapaport E, Koeppe J, Campbell TB, Wilson CC. Contribution of intestinal barrier damage, microbial translocation and HIV-1 infection status to an inflammaging signature. PLoS One. 2014;9(5):e97171. PubMed PMID: 24819230. Pubmed Central PMCID: PMC4018269. doi: 10.1371/ journal.pone.0097171

26. Vanuytsel T, Vermeire S, Cleynen I. The role of Haptoglobin and its related protein, Zonulin, in inflammatory bowel disease. Tissue Barriers. 2013;1(5):e27321. PubMed PMID: 24868498. Pubmed Central PMCID: PMC3943850. doi: 10.4161/tisb.27321

27. Gutsmann T, Muller M, Carroll SF, MacKenzie RC, Wiese A, Seydel U. Dual role of lipopolysaccharide (LPS)-binding protein in neutralization of LPS and enhancement of LPS-induced activation of mononuclear cells. Infect Immun. 2001;69(11):694250. PubMed PMID: 11598069. Pubmed Central PMCID: PMC100074. doi: 10.1128/ IAI.69.11.6942-6950.2001

28. Nystrom J, Stenkvist J, Haggblom A, Weiland O, Nowak P. Low levels of microbial translocation marker LBP are associated with sustained viral response after anti-HCV treatment in HIV-1/HCV co-infected patients. PLoS One. 2015;10(3):e0118643. PubMed PMID: 25785448. Pubmed Central PMCID: PMC4364767. doi: 10.1371/ journal.pone.0118643

29. Hileman CO, Turner R, N TF, Semba RD, McComsey GA. Changes in oxidized lipids drive the improvement in monocyte activation and vascular disease after statin therapy in HIV. AIDS. 2016;30(1):65-73. PubMed PMID: 26731754. doi: 10.1097/ QAD.0000000000000885

30. Sandler NG, Douek DC. Microbial translocation in HIV infection: causes, consequences and treatment opportunities. Nat Rev Microbiol. 2012;10(9):655-66. PubMed PMID: 22886237. doi: 10.1038/nrmicro2848

31. Chung CY, Alden SL, Funderburg NT, Fu P, Levine AD. Progressive proximal-to-distal reduction in expression of the tight junction complex in colonic epithelium of virally-suppressed HIV+ individuals. PLoS Pathog. 2014;10(6):e1004198. PubMed PMID: 24968145. Pubmed Central PMCID: PMC4072797. doi: 10.1371/journal.ppat.1004198

32. Obinna FC, Cook G, Beale T, Dave S, Cunningham D, Fleming SC, Claydon E, Harris JW, Kapembwa MS. Comparative assessment of small intestinal and colonic permeability in HIV-infected homosexual men. AIDS. 1995;9(9):1009-16. PubMed PMID: 8527072 .

\section{COPYRIGHT}

(C) Pathogens and Immunity 2017. This work is licensed under a Creative Commons Attribution 4.0 International License. To view a copy of this license, visit http://creativecommons.org/ licenses/by/4.0/ 